\title{
Laboreal
}

Volume $15 \mathrm{~N}^{\circ} 1$ | 2019

Trabalho e cooperação

\section{A cooperação e a dimensão coletiva da atividade, em um sistema de exploração de minério de ferro}

La cooperación y la dimensión colectiva de la actividad, en un sistema de explotación de mineral de hierro

La coopération et la dimension collective de l'activité, dans un système

d'exploration de minerai de fer

The cooperation and the collective dimension of the activity, in an iron ore exploration system

João César de Freitas Fonseca, José Newton Garcia de Araújo, Carlos Eduardo Carrusca Vieira e Rodrigo Padrini

\section{CpenEdition}

Journals

Edição electrónica

URL: http://journals.openedition.org/laboreal/1131

DOI: $10.4000 /$ laboreal. 1131

ISSN: 1646-5237

Editora

Universidade do Porto

Refêrencia eletrónica

João César de Freitas Fonseca, José Newton Garcia de Araújo, Carlos Eduardo Carrusca Vieira e

Rodrigo Padrini, «A cooperação e a dimensão coletiva da atividade, em um sistema de exploração de minério de ferro », Laboreal [Online], Volume 15 N$^{0} 1$ | 2019, posto online no dia 01 julho 2019,

consultado o 10 abril 2020. URL : http://journals.openedition.org/laboreal/1131 ; DOI : https://doi.org/ 10.4000/laboreal. 1131

Este documento foi criado de forma automática no dia 10 abril 2020.

Laboreal está licenciado com uma Licença Creative Commons - Atribuição-NãoComercial 4.0 Internacional. 


\section{A cooperação e a dimensão coletiva da atividade, em um sistema de exploração de minério de ferro}

La cooperación y la dimensión colectiva de la actividad, en un sistema de explotación de mineral de hierro

La coopération et la dimension collective de l'activité, dans un système

d'exploration de minerai de fer

The cooperation and the collective dimension of the activity, in an iron ore

exploration system

João César de Freitas Fonseca, José Newton Garcia de Araújo, Carlos Eduardo Carrusca Vieira e Rodrigo Padrini

\section{NOTA DO EDITOR}

Manuscrito recebido em dezembro/2018

Aceite após peritagem abril/2019

\section{Introdução}

1 O presente artigo visa discutir os resultados preliminares de uma pesquisa-intervenção em desenvolvimento, relativa ao trabalho de operadores de escavadeira elétrica a cabo que atuam em uma unidade de extração de minério de ferro, na região Norte do Brasil, sítio de uma das principais reservas minerais do país.

2 A expectativa da empresa, uma das maiores mineradoras do mundo, é de sempre aumentar o já alto nível da produtividade, atualmente estimado em 90 milhões de toneladas de minério de ferro por ano. $O$ investimento bilionário em um novo complexo mineral se deveu a pelo menos três fatores: a) as pesquisas que constataram o alto teor 
de minério de ferro da região; b) a queda expressiva do preço das commodities de minério de ferro, após 2014, o que impulsionou a empresa a investir num produto de excelente qualidade, comercializado mundialmente e com alta rentabilidade; c) a substituição do sistema convencional, que usa caminhões para transportar o minério extraído, por outro modelo denominado truckless. Este elimina o uso dos caminhões, agora substituídos por esteiras que conduzem o produto extraído até à usina de processamento. Esse novo sistema de exploração do minério de ferro, único no mundo, trouxe modificações relevantes para o processo produtivo e a organização do trabalho.

3 A descoberta das reservas minerais na região Norte do país remonta à década de 1960 . Em efetiva operação desde 2016, esse complexo extrativo é considerado, potencialmente, o maior do mundo, além da alta qualidade do teor do ferro $(66,7 \%)$ e sua baixa concentração de impurezas. Esse novo processo, ao eliminar caminhões e centenas de trabalhadores, requer um complexo sistema automatizado, desde a coleta do minério até seu carregamento em comboios que o conduzem aos portos marítimos. Nesse processo, o único elemento não automatizado são os operadores das escavadeiras que retiram o minério do solo, auxiliados por uma equipe de apoio ao seu redor.

4 A investigação que deu origem a este artigo iniciou-se em janeiro de 2018, fruto de uma demanda da empresa mineradora, que convocou pesquisadores de diversos núcleos científicos (técnico, cognitivo, clínico-físico e psicossocial) para atuarem em um projeto específico, voltado para o aprimoramento desses operadores de escavadeiras, então denominados Operadores de Alto Desempenho. O objetivo desse projeto, segundo documentos da empresa, é o desenvolvimento de habilidades e competências para um trabalho executado em ritmo intenso e acelerado - a escavação do minério -, visando ao alcance máximo de produtividade.

5 A expressão "alto desempenho" aplica-se usualmente a atletas profissionais, que devem atingir ou superar o limite de suas capacidades, em olimpíadas e grandes competições nacionais e internacionais (Samulsky, 2009). No vocabulário da gestão neoliberal, a expressão "atleta corporativo" tem sido apropriada, no sentido de extrair do trabalhador-atleta sua máxima performance. Há algum tempo que pesquisadores do trabalho, como Aubert e Gaulejac (1991), se referem a esse "devir atlético" e empresarial, típico da sociedade contemporânea "doente do tempo" e do "culto da urgência (Aubert, 2003). Neste mesmo sentido, Ehrenberg (2010) faz menção a um culto da performance, associando-a a um "esporte fora do esporte".

6 A demanda da organização ao nosso núcleo (o psicossocial) destinava-se a investigar os fatores psicossociais que afetam diretamente os operadores, no sentido de assegurar seu máximo rendimento. Desde a análise inicial dessa demanda, entendíamos que nossa contribuição não consistiria em ajustar instrumentalmente os trabalhadores às exigências de seu trabalho. Decidimos, então, propor uma pesquisa-intervenção que privilegiasse a abordagem coletiva, em vez da individual, a fim de possibilitar um desempenho baseado na cooperação entre esses trabalhadores. Nessa direção, apresentamos à empresa um projeto que se baseava na Clínica da Atividade (Clot, 2006, 2007a, 2007b, 2010, 2011, 2013, 2016), entendida como uma abordagem que privilegia a transformação da atividade de trabalho.

7 A despeito do foco na atividade e do objetivo comum de transformar o trabalho, a Clínica da Atividade se diferencia da Ergonomia da Atividade, afirmando-se como um contraponto à "divisão do trabalho", instituída no próprio campo de análise do trabalho, de acordo com a qual os ergonomistas deveriam se incumbir de analisar o 
trabalho e delegar a outros a responsabilidade de complementar essa análise, abordando as questões de ordem subjetiva (Clot, 2007b). A Clínica da Atividade busca superar esse divórcio entre atividade e subjetividade e restituir a questão do sentido para o "interior" da própria atividade, fundamentando-se no legado de autores como Lev Vygotsky, Aleksei Leontiev e Mikhail Bakhtin, e também de Georges Canguilhem e François Tosquelles (Clot, 2010).

Essa escolha implicava orientar nossa investigação em duas direções: 1) o trabalho dos operadores, que é realizado em duplas; 2) os modos de organização do processo produtivo, que envolve outros trabalhadores (técnicos, gerentes, gestores). As direções indicadas apontam para a necessidade de fortalecimento dos processos coletivos de trabalho, fundamentais na perspectiva da Clínica da Atividade e, neste artigo, articulados à noção de cooperação. No caso, tratava-se de uma alternativa à demanda de formação individual do "operador-atleta", baseada numa pretendida personalização da atividade dos operadores.

9 Em outras palavras, o objetivo principal deste artigo é discutir como a cooperação evidencia-se na atividade do operador de escavadeira a cabo, tanto no trabalho em duplas quanto na realização coletiva do processo extrativo de minério, explicitando assim os limites de uma formação de cunho individualizante.

10 A seguir, vamos tecer algumas considerações sobre o contexto da mineração no Brasil, com referências à corporação que nos encaminhou a pesquisa. Tentaremos também descrever, de modo sucinto, o sistema truckless.

\section{Mineração, sistema truckless e operadores de alto desempenho}

11 Segundo Amaral (2016), a mineração sempre esteve presente na história do Brasil. Afinal, o país detém um imenso patrimônio mineral, figurando como um dos maiores produtores e exportadores de minério do mundo. Além disso, os recursos minerais têm inúmeras utilidades na construção civil e na indústria siderúrgica. $O$ estado de Minas Gerais se destaca, historicamente, entre as rotas de exploração de pedras e metais preciosos, como o ouro. Foi nele que se iniciou a atividade mineradora no Brasil. A expansão dessa atividade no país ampliou-se significativamente com o surgimento de novas tecnologias e do incremento de pesquisas geológicas. Na década de 1990, houve maior abertura do mercado para empresas estrangeiras. No início do século XXI, ocorreram novos investimentos no setor em função da associação entre empresas nacionais e estrangeiras. Atualmente, a mineração ocupa, de acordo com o Departamento Nacional de Produção Mineral - DNPM (2016), um papel fundamental na economia e no processo de industrialização nacionais.

12 Ainda de acordo com o DNPM (2016), as substâncias metálicas como alumínio, cobre, estanho, ferro, manganês, níquel e ouro, correspondem à parcela dominante da produção mineral comercializada no país. Com transações financeiras que alcançam a casa dos bilhões de reais - em 2015, elas chegaram aos 67,5 bilhões -, o minério de ferro possui expressiva participação nessa soma, tendo sua produção concentrada nos estados de Minas Gerais e Pará. Assim, a exploração advinda desses dois estados correspondeu, em 2015 , a cerca de $80 \%$ de toda a produção nacional comercializada. $O$ estado do Pará, situado na região Norte, geograficamente a mais extensa do Brasil, 
abriga uma das principais reservas minerais do território nacional. De acordo com o Centro de Tecnologia Mineral - CETEM (2014), ele é considerado "a nova fronteira da mineração no país" (p. 6).

O método para se extrair o minério do solo exige uma complexa análise de fatores, tais como: características do minério, custos da mineração, tecnologia utilizada, garantia à segurança e aos impactos ambientais. A lavra a céu aberto (ou exploração de superfície) é o modelo tradicional que se pratica nessa região (Pinheiro, Oliveira, \& Mesquita, 2016; Palmeira, 2013; Mesquita, Marotta, Athar, \& Sebe, 2011).

Basicamente, o ciclo de exploração do minério de ferro, na mina em que se adotou o sistema truckless, apresenta as seguintes etapas: a) o desmonte das rochas, por perfuração do solo e detonação; b) a acomodação do minério em amontoados, também denominados bancadas ou frentes de lavra; c) a escavação, ou seja, a coleta desse produto por meio de escavadeiras elétricas a cabo, que o descarregam num britador (moega); d) da moega, o minério passa a uma esteira que o leva até uma central de processamento final; e) carregamento do minério em comboios que seguem até os portos marítimos.

Para se ter uma ideia da complexidade do sistema, do qual o operador é parte fundamental, há que se compreender a totalidade do processo, como detalharemos a seguir.

pós as fases do desmonte e da acomodação do minério em bancadas, o sistema de extração, processamento e transporte compreende os seguintes equipamentos e/ou instalações, conforme ilustrados na Figura 1:

$1^{\circ}$ ) as escavadeiras elétricas a cabo, que extraem o minério a céu aberto;

$2^{\circ}$ ) os britadores móveis ou moegas, que recebem o material despejado pelas escavadeiras e iniciam o processo de cominuição do minério, ou seja, a sua fragmentação em pedaços menores e redução à granulometria desejada;

$\left.193^{\circ}\right)$ as correias de longa distância, que levam o minério de qualidade à usina de processamento ou às pilhas de estéril, isto é, material resultante da atividade mineradora, porém sem valor comercial, e de canga, espécie de rejeito que poderá ser utilizado comercialmente;

$4^{\circ}$ ) a usina, onde o minério é beneficiado a seco, ou seja, tratado com a umidade natural, sem uso de água, então preparado para ser comercializado e estocado em pátios, para equilibrar o ritmo entre extração e processamento;

$\left.215^{\circ}\right)$ a estação de carregamento dos comboios;

6) a estrada de ferro, pela qual o minério é transportado até o terminal marítimo;

$7^{\circ}$ ) o terminal ou porto;

$8^{\circ}$ ) os navios, que levarão o produto aos seus compradores. 
Figura 1 - Extração, processamento e transporte

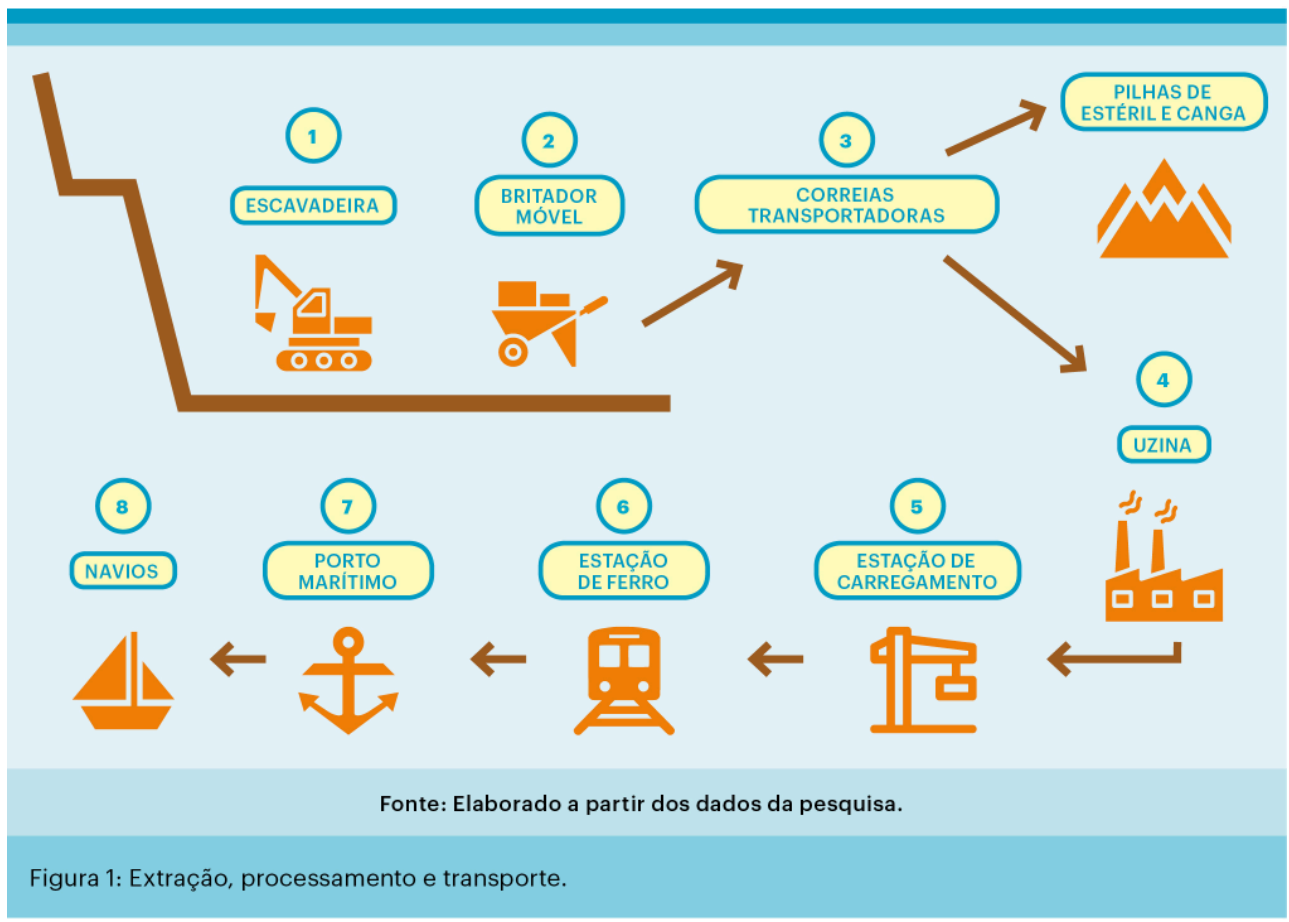

Fonte: Elaborado a partir dos dados da pesquisa

No complexo mineral analisado, existem quatro sistemas ou minas em operação, posicionados em locais distintos. Cada um desses sistemas é composto por uma escavadeira, um britador móvel e uma correia transportadora móvel que se conecta ao eixo central de correias transportadoras fixas, de modo a permitir que o material escavado flua na sequência ilustrada na Figura 1.

6 Em todas as instalações e processos, temos trabalhadores operando máquinas ou monitorando o seu funcionamento, presencialmente ou à distância, por meio de dispositivos eletrônicos analógicos ou digitais.

função do caráter contínuo e dinâmico de todo esse processo, a comunicação é intensa e efetuada de forma presencial ou mediada por rádios portáteis. $\mathrm{O}$ processo produtivo é acompanhado, principalmente, pelo Centro de Controle Operacional (CCO), uma instância técnica responsável pelo monitoramento remoto das condições dos equipamentos, fluxo da produção e regulação de condições específicas relacionadas ao maquinário. Por meio de painéis eletrônicos digitais, câmeras e imagens de satélite, o CCO supervisiona as diferentes etapas do processo e opera com o objetivo de assegurar a estabilidade e a continuidade da produção, além da sincronização entre os quatro sistemas e a prevenção de panes e acidentes.

$\mathrm{Na}$ etapa da escavação do minério de ferro é que atuam os operadores "de alto desempenho", sujeitos de nosso estudo. Sua atividade, realizada em ritmo contínuo e sequencial, consiste em manejar a escavadeira posicionada diante da frente de lavra, a fim de colher o minério e despejá-lo dentro da moega, diferentemente do sistema tradicional, no qual o minério é despejado na caçamba de um caminhão que o transporta até o britador. Ou seja, exclui-se a necessidade do uso de caminhões, como intermediários entre a escavação e o despejo do material. 

manobram a escavadeira. No entanto, esse manejo da máquina é individual. Em um turno ininterrupto de doze horas, na cabine - organizado de modo que cada uma das quatro duplas, dois operadores por sistema, trabalhe por três dias consecutivos, seguidos de três dias de folga - os dois trabalhadores se revezam na escavação, na razão de seis horas para cada um. Assim, enquanto um realiza a atividade, o outro, que chamaremos de "operador auxiliar", fica aparentemente em repouso. Ele deve, porém, ficar à disposição do colega, em estado permanente de alerta, mesmo lhe sendo permitido ocupar-se de atividades paralelas (escutar música, ler, utilizar o telemóvel, etc.), atividades necessárias, aliás, para que ele se recupere do desgaste físico e mental. andamento o resto do processo, que é todo automatizado. Ele deve, ao mesmo tempo, inspecionar permanentemente o bom funcionamento da escavadeira, além de a locomover na "praça" (a grande área onde se encontram as bancadas do minério e a frente de lavra), quando é necessário o reposicionamento dos equipamentos para prosseguir com a escavação.

31 Com base na observação do trabalho dos operadores e em suas verbalizações, além do contato com os técnicos e gestores, pode-se resumir o ciclo de sua atividade em quatro etapas: (1a) escavação do minério com as garras da caçamba, que avança na frente da lavra; (2a) elevação e giro da caçamba carregada, em direção à moega; (3a) abertura da tampa da caçamba, que descarrega o minério na moega, e; (4a) giro de retorno da caçamba para nova escavação da lavra.

As quatro etapas estão ilustradas na Figura 2:

Figura 2 - Ciclo de extração e carregamento de minério de ferro realizado pelo operador

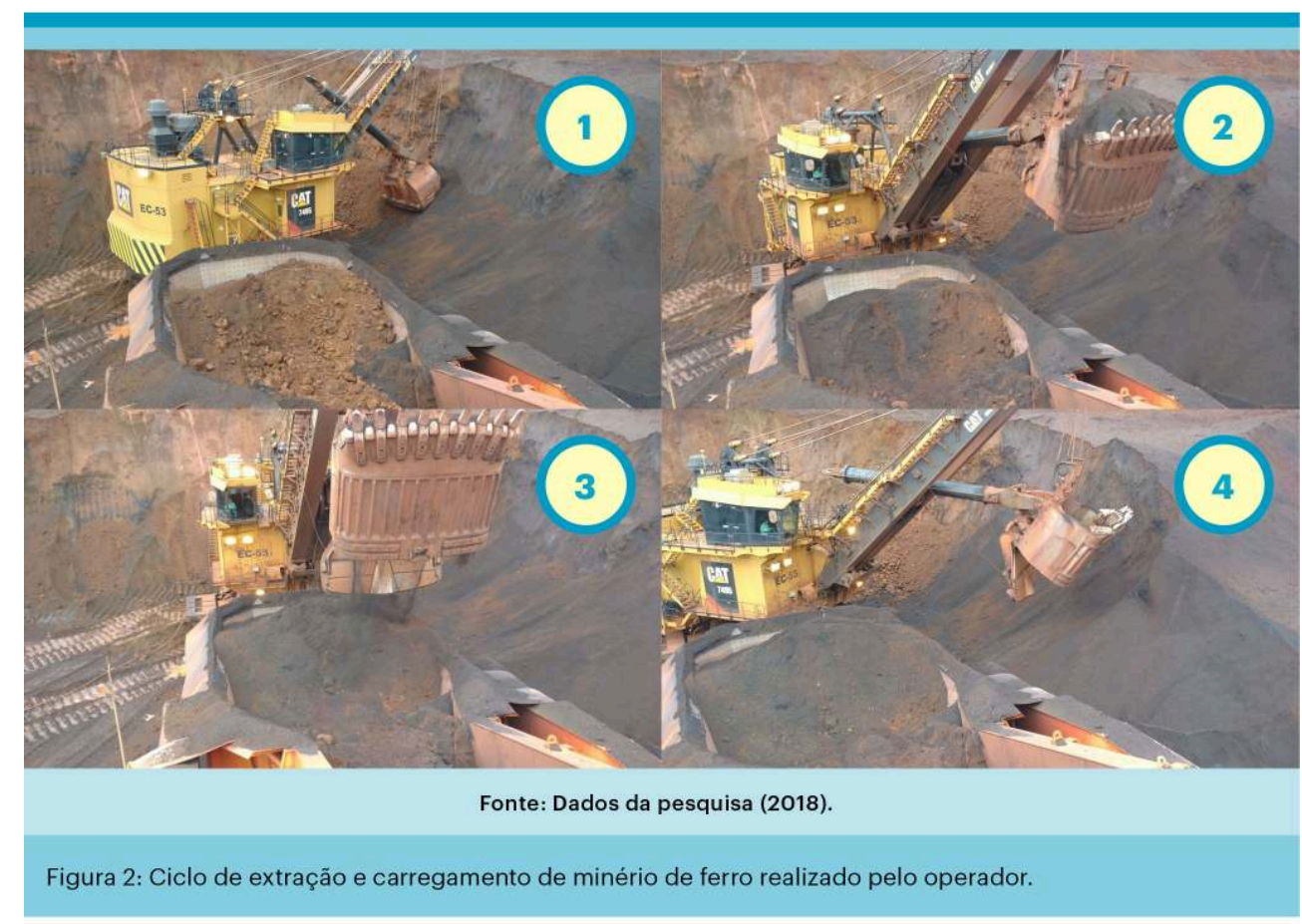

Fonte: Dados da pesquisa (2018)

Laboreal, Volume $15 \mathrm{~N}^{\circ} 1 \mid 2019$ 
33

importante ressaltar que a atividade do operador de escavadeira é feita em cooperação com outras atividades, seja à distância - através da comunicação pelo rádio, por exemplo -, seja nas proximidades espaciais do equipamento. Aí se localizam os técnicos ou chefes imediatos que gerenciam a extração; os operadores de trator e patrola, que auxiliam na limpeza e organização da "praça"; os profissionais que atuam na manutenção preventiva ou inspeção das máquinas; e aqueles que atuam para definir os próximos pontos de escavação e determinar o deslocamento dos equipamentos. Detalharemos como os aspectos descritos até aqui remetem à noção de cooperação em nossa discussão dos resultados.

\section{Entre premissas teóricas críticas e demandas de produtividade}

Os fundamentos teórico-metodológicos que norteiam nossa pesquisa, já dissemos, são os pressupostos teórico-epistemológicos da Clínica da Atividade. Eventualmente, a ela ajuntaremos contribuições de outras abordagens clínicas do trabalho que, sob diferentes olhares, também investigam a atividade de trabalho, visto ora como produtor de saúde, ora de adoecimento. A análise e as eventuais intervenções na organização e nas condições de trabalho têm em vista, quando necessário, sua transformação, no sentido da proteção e promoção da saúde do trabalhador, da prevenção de adoecimentos e de acidentes de trabalho (Bendassolli \& Soboll, 2011; Lima, 2007).

Ao comentar as transformações no trabalho e os desafios da Ergonomia, Abrahão e Pinho (2002) afirmam que, na atual complexidade dos sistemas produtivos, "a competência dos trabalhadores constitui uma variável determinante. Ela se manifesta na sua capacidade em lidar com universos dinâmicos e na habilidade em adaptar rotinas, em face da variabilidade do processo de trabalho" (p. 50). As autoras acrescentam que aí intervêm diversos fatores, sujeitos a variações permanentes. No caso de sistemas automatizados, como a extração mineral aqui estudada, julgamos pertinente ir além da análise individualizada dos processos cognitivos do operador, suas habilidades motoras e condições físico-clínicas. Para nós era também crucial analisar a dimensão coletiva de sua atividade, que comporta permanentes imprevistos e ampla variabilidade.

A demanda desta investigação partiu da área de Pesquisa e Desenvolvimento (P\&D) da empresa, que buscava viabilizar as condições de trabalho dos operadores, em função da natureza repetitiva e desgastante de uma tarefa que requer bastante destreza e rapidez de execução. Já vimos que, nesse novo processo de mineração, o operador de escavadeira é visto como a principal, se não a única força humana de trabalho que tem contato direto com o insumo (minério). Ele é o ponto de partida, é quem determina a maior ou menor produtividade do sistema, em função da quantidade do minério que coleta na escavadeira e libera para o mecanismo automatizado que executa o restante das operações - britagem, condução em esteiras, refinamento do minério e carregamento nos comboios. Numa visita ao campo, ouvimos de um técnico: "Se [o operador] parar aqui, vai faltar material lá na usina... O que você tá jogando [na moega], tá saindo, você tem aquela continuidade, mina-usina, se sai daqui dezesseis mil, lá tá arrecadando dezesseis mil também. Entende?" (E17).

Laboreal, Volume $15 \mathrm{~N}^{\circ} 1$ | 2019 

do sistema truckless. A esse respeito, lembramos que, em sua crítica ao taylorismo, Canguilhem (2016) aponta o risco de se "reduzir o trabalho humano a um mecanismo inanimado, regulado em função do maior rendimento econômico" (p. 115), de modo a atrelar o homem à máquina e tratar ambos sob o mesmo ponto de vista métrico $\mathrm{e}$ quantitativo.

lógica, adotada pela empresa, reproduzida pelos gestores e, em alguns casos, até mesmo pelos trabalhadores, distancia-se substantivamente da orientação crítica e clínica que sustenta os referenciais teóricos presentes em nossa proposta à empresa, embora soubéssemos que o objetivo do "alto desempenho" dos operadores era um item inegociável com a gestão. Isso repercutiu, evidentemente, em nossas discussões internas, à maneira de uma dramatique, no sentido de Schwartz (1996, p. 104), pois estávamos desafiados a fazer escolhas, a "arbitrar entre valores diferentes e, às vezes, contraditórios", na condução de nosso trabalho. As estratégias adotadas por nossa equipe de pesquisa para negociar a entrada em campo, inclusive com a adoção de metodologias que estimulavam a participação dos trabalhadores, está sendo objeto de registro em outro artigo (Monteiro, Araújo, \& Fonseca, 2018).

Por outro lado, acreditávamos que nossa proposta de intervenção poderia induzir, minimamente, a práticas até então inexistentes na gestão do trabalho. Em contraposição à visão puramente instrumental e centralizadora, dominante no gerencialismo neoliberal, sugerimos, por exemplo, a criação de espaços de interlocução, da absorção dos "saberes investidos" (em aderência com a atividade) (Schwartz, 2011), ou seja, da valorização das experiências ou do savoir-faire dos trabalhadores, visando à ampliação de seu poder de agir (Clot, 2010), à melhoria de suas condições de saúde e segurança no trabalho. Para nossa satisfação, o projeto que apresentamos, como alternativa ao desenvolvimento do "trabalhador-atleta", foi aceito pela gestão, que se mostrou aberta à nossa proposta teórico-metodológica, mesmo que isso implique permanentes negociações.

Não cabe aqui repassar os fundamentos teórico-metodológicos da Clínica da Atividade, referência central do projeto apresentado à empresa. Vamos, no entanto, inserir alguns conceitos e pressupostos desta e de outras disciplinas clínicas do trabalho no decorrer deste artigo, quando for relevante fazê-lo, para melhor fundamentar nossa argumentação.

41 Julgamos também oportuno assinalar que a Clínica da Atividade, de maneira semelhante às outras abordagens clínicas do trabalho, tem ganhado espaço nos grupos de pesquisa brasileiros, gerando inclusive controvérsias quanto às nuances que passam a adquirir, em contextos diferentes daqueles em que foram originariamente propostas (Fonseca \& Oliveira, 2013; Osório, Barros de Barros, \& Louzada, 2011).

\section{Metodologia}

Neste estudo, privilegiamos o uso de metodologias qualitativas, por meio de dispositivos que convocam os próprios sujeitos a refletir sobre suas práticas (Bendassolli \& Soboll, 2011). Sendo assim, pressupomos a indissociabilidade entre pesquisa e ação, à maneira de uma intervenção voltada também para a produção de dados e produção de conhecimentos, em nossa interação com o campo. Diríamos, então,

Laboreal, Volume $15 \mathrm{~N}^{\circ} 1$ | 2019 
com Thiollent (2008), que "o estudo se desenrola paralelamente ao acompanhamento da ação” (p. 57), em uma perspectiva clínica.

Para Lhuilier (2014), "trata-se, ao mesmo tempo, de compreender para transformar e de transformar para compreender, o que inscreve a clínica do trabalho numa perspectiva de pesquisa-ação" (p.8). Dessa forma, a intervenção busca produzir conhecimento sobre o trabalho e nele intervir, por meio da mobilização da capacidade dos trabalhadores de criar e reinventar sua atividade profissional (Silva, 2014).

44 A pesquisa teve como público participante 36 (trinta e seis) trabalhadores que exercem a função de operadores de escavadeira do sistema truckless, na já citada área de mineração, situada na região Norte do país. 0 estudo de campo vem sendo desenvolvido desde janeiro de 2018, tendo sido realizadas, até hoje, quatro viagens ao local, com duração média de três dias. Cada estadia incluiu visitas às instalações da mina, em especial aos chamados sistemas de escavação. De acordo com as condições possíveis (quando a produção é ininterrupta), foram realizadas entrevistas e observação dialogante (Dujarier, 2016), ou seja, observação in situ da atividade dos operadores e dos gestores (técnicos, supervisores e gerentes), numa interlocução que permite a explicitação da atividade. Em alguns momentos, os pesquisadores acessavam os demais espaços do complexo da mineração, a exemplo do CCO, além de buscar outros contatos informais com os mesmos técnicos, gerentes, gestores e outros trabalhadores do nível operacional.

45 Entres os procedimentos para a coleta do material empírico, listamos: entrevistas individuais, observação nos locais de trabalho, filmagens, análise documental e diários de campo, além de duas técnicas utilizadas pela Clínica da Atividade: a instrução ao sósia e a autoconfrontação.

46 Na instrução ao sósia, o pesquisador pede ao sujeito, num suposto jogo de papéis, para assumir o seu lugar de trabalhador: "Suponha que eu seja seu sósia e que amanhã vou substituí-lo em seu local de trabalho. Quais instruções você deveria me transmitir para que ninguém perceba a substituição?" (Clot, 2007a, p. 144). A partir desse momento, o trabalhador torna-se instrutor e deve ajudar o seu sósia a orientar-se sobre o que deve fazer, o que deixa de fazer, o que poderia fazer, mas não faz, etc. Assim, ele amplia as possibilidades de conhecimento e de transformação do trabalho, revelando a si mesmo modos de fazer, por vezes não regulados ou não apropriados reflexivamente.

A autoconfrontação consiste em uma análise da atividade, por meio de um diálogo entre o trabalhador e o pesquisador, a partir de um registro audiovisual da cena de trabalho de um ou mais trabalhadores. Assim, o trabalhador se desloca de sua "posição comum" e se vê, na própria atividade, sob nova perspectiva (Clot, 2011). Na autoconfrontação simples, o sujeito comenta com o pesquisador a sequência filmada de sua atividade. $\mathrm{Na}$ autoconfrontação cruzada, cada trabalhador discute as mesmas sequências filmadas (Silva, 2014), tanto com o pesquisador quanto com o colega de trabalho também filmado.

48 A instrução ao sósia e a autoconfrontação produzem uma atividade sobre a atividade, ou seja, uma atividade de análise sobre a atividade de trabalho, revelando assim sua dimensão encoberta, que poderíamos aproximar do conceito de real da atividade. Para Silva (2014), "é pela experimentação transformadora que a atividade de trabalho pode mostrar seus segredos [...]" (p. 88). Ao deslocar-se para a posição de observador e intérprete da própria atividade, o trabalhador pode compreendê-la melhor e projetar, 
para si e para o coletivo de trabalho, novas estratégias de regulação. Ao fazê-lo, em controvérsias ou debates com o pesquisador clínico, o sujeito se libera "tanto quanto possível, de suas maneiras habituais de pensar e dizer suas atividades" (Clot, 2010, p. 37).

Mostramos a seguir, no quadro 1, alguns dados relativos aos trabalhadores que participam deste estudo, até o momento, e suas modalidades de participação.

Quadro 1 - Caracterização dos trabalhadores e técnicas utilizadas

\begin{tabular}{|c|c|c|c|c|c|c|}
\hline SUJEITO & CARGO & $\begin{array}{l}\text { TEMPO NA } \\
\text { ORGANIZACCÅO } \\
\text { (ANOS) }\end{array}$ & ENTREVISTA & $\begin{array}{l}\text { INSTRUÇÃO } \\
\text { AO SÓSIA }\end{array}$ & $\begin{array}{l}\text { AUTO- } \\
\text { CONFRONTAÇÃOO } \\
\text { DIRETA }\end{array}$ & $\begin{array}{l}\text { AUTO- } \\
\text { CONFRONTAÇÁO } \\
\text { CRUZADA }\end{array}$ \\
\hline E01 & OPERADOR & 14 & $x$ & & & \\
\hline E02 & OPERADOR & 4 & $x$ & $\mathrm{x}$ & & \\
\hline EO3 & OPERADOR & 9 & $x$ & & & \\
\hline E04 & OPERADOR & 10 & & & & $x$ \\
\hline E05 & OPERADOR & 11 & $\mathrm{x}$ & & & \\
\hline EO6 & OPERADOR & 7 & $x$ & & & \\
\hline E07 & OPERADOR & 12 & $\mathrm{x}$ & & & \\
\hline E08 & OPERADOR & 2 & $x$ & & & \\
\hline EO9 & OPERADOR & 10 & $x$ & & $x$ & $\mathrm{x}$ \\
\hline E10 & OPERADOR & 10 & & $x$ & & \\
\hline E11 & OPERADOR & 3 & & $x$ & & \\
\hline E12 & OPERADOR & 7 & $x$ & & & $x$ \\
\hline E13 & OPERADOR & 14 & $x$ & $x$ & & $x$ \\
\hline E14 & OPERADOR & 11 & $x$ & $x$ & & \\
\hline E15 & OPERADOR & 10 & $x$ & & & \\
\hline E16 & TECNICO & NAO INFORMADO & $x$ & & & \\
\hline E17 & TECNICO & NĀO INFORMADO & $\mathrm{x}$ & & & \\
\hline \multicolumn{7}{|c|}{ Fonte: Elaborado pelos autores com base na pesquisa de campo. } \\
\hline
\end{tabular}

Fonte: Elaborado pelos autores com base na pesquisa de campo

A discussão preliminar dos dados, a seguir, serviu-se das etapas da análise de conteúdo, formuladas por Bardin (1977): a pré-análise; a exploração do material; e o tratamento dos resultados, ancorado em inferências e interpretações. Foram também criadas categorias de análise, com avaliação provisória, já que a pesquisa ainda se encontra em desenvolvimento. Dentre estas categorias, privilegiou-se a dimensão coletiva da atividade, na qual se evidenciam os processos de cooperação, no interior de toda a equipe, não só entre os operadores.

51 Este estudo segue as normas brasileiras de pesquisas, previstas pela Comissão Nacional de Ética em Pesquisa (CONEP), envolvendo seres humanos. Dentre elas citamos: a obrigatoriedade de uso do Termo de Compromisso (Carta de Anuência) assinado pela instituição, autorizando sua execução; o parecer do Comitê de Ética em Pesquisa (CEP) da PUC Minas, que aprovou o presente projeto, sob o registro 2.840.710; e a assinatura de Termo de Consentimento Livre e Esclarecido (TCLE) por todos os trabalhadores que se dispuseram a participar da investigação. 


\section{Resultados e discussão}

Nossa primeira constatação, relativa à análise da atividade dos operadores de escavadeiras a cabo, foi que esta não se resume à mera execução de protocolos e operações. Com efeito, para agir, eles ponderam normas e valores, filtram préocupações pessoais e sociais, colocando-se num campo de múltiplas relações. Assim, ao mesmo tempo em que a produtividade lhes é exigida como valor central, eles levam também em conta a própria segurança, a proteção do maquinário e das instalações, a preparação e a manutenção da área em que atuam, cientes de que sua atividade é realizada em um circuito coletivo e sempre endereçada a outros agentes do processo produtivo. Vejamos um relato:

Não é só encher a concha e jogar lá dentro, tem todo um processo para fazer, manter a limpeza na frente da máquina, não deixar bloco passar por baixo, pode danificar algum componente lá, na estrutura da parte inferior da máquina. Então, tem todo um processo que, às vezes o cara vê a gente jogando um material ali, e pensa que é só aquilo ali (E09).

De acordo com os operadores, a litologia do material escavado, isto é, sua composição mineralógica e as suas condições específicas (se é mais grosso ou mais fino, mais ou menos granulado, se tem blocos ou não, se está mais ou menos úmido, se é mais ou menos resistente à escavadeira) são variabilidades importantes em sua atividade, impactando, por exemplo, seu modo operatório, o ritmo de seu trabalho e decisões em relação ao posicionamento dos equipamentos junto à frente de lavra.

A unidade de extração de minério de ferro, aqui estudada, é subdividida em quatro sistemas ou minas, como já dissemos. Cada um deles conta com uma escavadeira elétrica a cabo, um britador móvel e um conjunto de correias transportadoras (beltwagon), todos interconectados, compondo o conjunto do sistema. As correias ou esteiras transportadoras realizam o escoamento da produção para as demais instalações, nas quais o material será tratado e preparado para a comercialização.

Com base nos resultados obtidos até o momento, vimos que a dimensão coletiva das operações, que associamos à noção de cooperação, é intrínseca ao desenvolvimento da atividade dos operadores. Vimos também que a cooperação não se reduz à atividade das duplas, pois diz respeito a toda a equipe acima descrita. Ela ocorre, de forma estrutural, ao longo de todo o processo produtivo, o que se confirma pelo fluxo intenso de comunicação entre os diferentes agentes desse processo.

Assinalamos que a noção de cooperação não é tomada, aqui, como equivalente ao "desejo de colaborar", ainda que isso seja fundamental, mas como dimensão social inerente ao trabalho humano. Numa perspectiva clínica, ressalta-se o caráter policêntrico de toda atividade, endereçada não só ao objeto da tarefa, mas ao outro, de cujas atividades somos também destinatários (Clot, 2007a, 2013). Enfim, cooperar, operar simultaneamente ou prestar cooperação, é uma dimensão ontológica inelutável da atividade, se considerarmos que a produção de todo o patrimônio cultural humano só é possível mediante algum esforço conjunto.

O trabalho comporta, além disso, não apenas dimensões gestuais, físicas, cognitivas e afetivas, mas uma dimensão ética (Lima, 2002). Com efeito, trabalhar é gerir as adversidades de situações reais, na realização de tarefas, mas é ainda deparar-se com valores e normas, num intercâmbio da produção material e da sociabilidade. 
58 A noção de cooperação se apresenta, por isso, como elemento basilar de nossas análises e intervenções, permitindo-nos uma compreensão do trabalho como processo histórico, social e material. Essa perspectiva nos orienta, fundamentalmente, nesta pesquisa, no sentido de deslocar a metáfora individualizante e reducionista do "operador-atleta" ou "de alto desempenho", tal como pretendida pela gestão da empresa mineradora. Como vimos acima, a produção depende dos esforços conectados de diversos profissionais que atuam no sistema truckless, seja na área extrativa do minério, seja nas demais dependências do complexo minerador, como o CCO. Como foi dito anteriormente, este centro monitora as operações dos quatro sistemas de escavação e os demais equipamentos a eles relacionados. É gerenciado por técnicos que atuam através de sofisticados painéis de controle dos sistemas automatizados, a fim de viabilizar o fluxo contínuo do processo produtivo e prevenir possíveis problemas. O CCO pode, por exemplo, mediante solicitação do operador da escavadeira, alterar a velocidade do "alimentador de sapatas", sistema que funciona no britador móvel e que determina a velocidade de escoamento do material depositado na moega para as etapas seguintes, impactando a atividade produtiva de toda a mina.

59 O fenômeno da cooperação é, pois, evidente, no complexo funcionamento do sistema. Ele se contrapõe à pretensão de se centrar o processo produtivo só no operador de alto desempenho. Por outro lado, é equivocada a pressuposição de que a eficiência do operador resulta apenas de sua vontade individual, supostamente autônoma e desvinculada de uma rede de relações sociais, organizacionais e materiais. Neste sentido, é questionável centrar nele a avalição de seu desempenho. Lembremos, a esse respeito, a formulação teórica de Clot (2013), segundo a qual a atividade de trabalho é, simultaneamente, pessoal, interpessoal, transpessoal e impessoal, e que ela opera no entrelaçamento dessas dimensões (Santos, 2006).

Observemos, além disso, que Clot (2016) problematiza a cooperação, ao propor a noção de "cooperação conflitual", necessária, segundo ele, para o desenvolvimento da atividade. Esta noção parece paradoxal, mas configura a conflitualidade indispensável ao diálogo e a suas controvérsias, capazes de levar a novas vias de ação e à transformação de situações nocivas do trabalho. Assim, a discussão sobre os critérios de um trabalho bem feito gera conflitos que quebram o monólogo do pensamento.

61 Com base nessas considerações, pretendemos evidenciar como a cooperação se apresenta no trabalho em duplas e na realização coletiva do processo extrativo. Cumpre notar que, nos depoimentos abaixo citados, usaremos uma codificação alfanumérica para preservar a identidade dos trabalhadores entrevistados.

\section{0 trabalho em duplas}

62 A escavadeira elétrica a cabo, como já se sabe, funciona com uma dupla de operadores, um que efetivamente maneja a máquina e outro que, permanecendo dentro da cabine, fica disponível para eventuais intervenções, ao mesmo tempo que se recupera do desgaste físico e mental que a atividade acarreta. A dupla tem autonomia parcial para organizar o tempo de revezamento, durante as 12 horas do turno trabalhado. Isso é visto de maneira positiva pelos operadores. A proposição inicial era de um revezamento a cada três horas, garantindo um ritmo aceitável entre a operação efetiva da máquina e o repouso "em vigília". Ao término do turno, outra dupla assume as operações. A troca 
ocorre nos quatro sistemas que compõem a unidade de extração. Um operador comenta:

[...] quando eu tava com ele aqui dividindo o sistema dois, a gente pegava de dois em dois... Não deixava ficar muito tempo não, porque é bobagem, já passou o tempo bom pro outro operador [...] um fica descansando aqui, enquanto o outro tá operando. Supervisor, técnico, normalmente não dão opinião, não... eles não falam, pra nos dar autonomia mesmo (E15).

63

\section{colega. A experiência de situações prejudiciais atesta a atual consciência dessa postura:}

Acredito eu, que diminui o risco de acidente, devido a quê? São duas mentes pensando diferente, então mesmo se eu não estiver na operação, no controle da máquina, meu colega, ele tá ali atento a qualquer... adversidade que venha a acontecer (E02).

Cada caso é um caso, entendeu? Parece que eu gosto do cara aqui me olhando, às vezes não. Às vezes esse cara me incomoda, tira minha concentração [...] você pensa uma escavadeira dessa, enorme, rapaz, a responsabilidade é grande, tu tem que ter ritmo, tem que ter qualidade, tem que ter atenção. Qualquer foco que é tirado, tu vê um vídeo que ele tá vendo, tira tua atenção (E14).

Por outro lado, o auxiliar ajuda efetivamente o colega, ao observar situações imprevistas no trabalho, ao substituí-lo, quando necessário, ao realizar procedimentos que o outro não pode fazer, como sair da máquina e examinar os "pontos cegos", na proximidade da escavadeira com a bancada, ou da escavadeira com o britador móvel, evitando assim os riscos inerentes às situações emergentes. Caso o operador principal esteja sozinho, o que às vezes ocorre, ele precisa paralisar a atividade:

Às vezes você precisa fazer alguma manobra que vai passar perto de um outro equipamento ou vai passar perto de uma bancada e... já aconteceu comigo algumas vezes, acho que já aconteceu com o menino também, de você largar da tua poltrona e sair na porta pra dar uma olhada, se tá passando muito perto, entendeu? (E03).

O revezamento autônomo entre os operadores, segundo seus critérios de tempo, é também uma estratégia de cooperação que previne a fadiga e a queda do ritmo de produção:

Tem que ser umas três horas pra você não se desgastar tanto, porque gera uma fadiga depois das três horas. Por isso que eu falo que é importante ter dois operadores numa máquina (E02). 

dupla, embora ela seja essencial, no sistema truckless. Alguns depoimentos atestam que é comum o operador trabalhar sozinho, sem poder ir ao banheiro, levantar-se para se "esticar" ou descansar para restaurar suas condições físicas e psicológicas. Com efeito, várias situações podem fazer com que os operadores trabalhem sozinhos na cabine da escavadeira. Dentre as mais comuns, identificamos: férias, afastamento por motivo de saúde, mudanças de escala e reorganização das equipes por critério da gestão.

O projeto é pra ser os dois operadores em cada equipamento, não é isso? Quando temos dois, dá sim, mas quando não temos dois, temos só um, aí não dá, não [...] acontece, demais, até mais tempo (E03).

Se você rodar seis horas direto, você tá no equipamento e tá rodando seis horas direto... você não vai poder parar ali, não vai poder parar a máquina. Você ir ali e beber uma água ou querer ir ao banheiro, você não tem como (E08).

Nesses casos, os operadores temem pedir permissão (para ir ao banheiro ou tomar água), por receio de diminuírem a produtividade e serem mal avaliados pela gerência. Esse mal-estar prejudica a produção, pois o sujeito se divide entre as exigências da tarefa, as necessidades fisiológicas que o constrangem e o medo da avaliação negativa. Há mesmo queixas contra essa conduta da gestão.

A vontade deles de produzir muitas vezes coloca a gente em uma situação difícil e aí muitas vezes, quando você questiona muito, eles acham que você é muito questionador (E13).

Por outro lado, há relatos que apontam para traços de resistência a tais imposições, geradoras de sofrimento, no exercício da atividade:

Eles não gostam que parem não, né? [não é?] Mas eu, se eu me sentir cansado, eu paro (E04).

No conjunto dos depoimentos, verificou-se a importância atribuída pelos participantes ao entrosamento da dupla. Ele é relevante para a prevenção da fadiga, de acidentes, para a manutenção da atenção e da concentração e, até mesmo, para o aumento da produtividade, tudo isso convergindo para a construção e a preservação da saúde no trabalho.

\section{Dimensão Coletiva do Processo Produtivo}

$\mathrm{Na}$ ótica do caráter policêntrico da atividade, envolvendo o sujeito, o objeto e o outro, entendemos que o fazer do operador de escavadeira é mediado pelo coletivo de trabalho, pelas demais atividades de outros profissionais. Um dos técnicos diz:

Você já chega imaginando que são quatro sistemas, aí se acaba a lavra, tem que locomover esse sistema. Aí eu tenho que saber os outros três, o tempo que têm para, às vezes, não casar duas locomoções no mesmo horário (E17).

Os operadores, por sua vez, relatam como os eventos ocorridos em outras unidades justificam e afetam suas escolhas individuais: 
A gente tem que estar trabalhando e tem que estar antenado no que está acontecendo, no cenário que está acontecendo nos outros sistemas, né? (E09).

Como estavam todos os outros parados, fiz uma operação mais difícil para poder tentar esperar o outro sistema rodar. Eu coloquei ela [a escavadeira] numa posição mais difícil pra eu operar, entendeu? Eu percebi que os outros sistemas estavam todos parados, né? E precisava produzir. Aí, mesmo que ficasse mais difícil, a gente conseguia manter mais tempo ele rodando (E04).

73 A decisão do operador, neste caso, foi uma forma indireta de cooperação com os técnicos e o restante da equipe, enquanto estes tentavam regular as falhas do sistema. Assim, a atividade de um é dependente do restante da cadeia produtiva, como relatam os operadores:

Noventa milhões de toneladas anuais. Então [o sistema] foi projetado pra dar esses resultados. Os investidores investiram fortunas de dinheiro foi pra isso, pra esse resultado. E esse resultado é tirado de nós, nós escavadeiristas, nós manutenção, nós apoio, ou seja, o conjunto inteiro vai produzir as noventa milhões de toneladas por ano [...] isso aqui é um elo, né, uma corrente, cada um depende um do outro pra poder rodar (E14).

Eu conheço gente de outro turno que, quando me vê, chega e fala: oh bicho, eu estou triste porque eu não produzi ontem, eu fiquei parado... não produzi. Quer dizer... tem pessoas que, por não rodar e atingir a meta dele, fica preocupado [...] embora, se não rodou, não é problema da gente... o problema é do sistema que não tá rodando (E13). espaços institucionalizados para uma discussão coletiva sobre o planejamento do trabalho, de maneira a partilharem conhecimentos e experiências comuns às suas distintas atividades, podendo daí ocorrer eventuais desentendimentos entre eles. Além disso, nas entrevistas, nas observações e nas autoconfrontações, observou-se, entre os operadores, a constante referência à experiência profissional individual para justificar escolhas e comportamentos, com poucas referências ao "nós", como conjunto dos trabalhadores.

77 A própria organização do trabalho (operar em escavadeiras, dentro de uma cabine, por horas, em quatro sistemas distintos e distantes) contribui para uma fragmentação do coletivo de trabalho. Os operadores pouco se encontram e não possuem espaços coletivos de convivência e diálogo. 
Com base nessa percepção, discutimos a necessidade de sistematização de um espaço de produção e troca de conhecimentos entre todos os atores do sistema truckless.

\section{0 incremento da participação como estratégia de fortalecimento do gênero profissional e da cooperação}

79 O conceito de gênero profissional designa, como sabemos, "um sistema aberto de regras impessoais, não escritas, que definem, num meio dado, o uso dos objetos e o intercâmbio entre as pessoas" (Clot, 2007, p. 50). Em outras palavras, é uma espécie de rascunho social que indica as relações dos indivíduos entre si, ligadas ao seu agir. Compreendido como um "repertório disponível que pré-organiza a atividade" (Lima, 2007, p. 100), o gênero profissional não se traduz apenas como a possibilidade de pertencimento de um indivíduo a um coletivo, mas como um recurso para a ação individual que é, simultaneamente, produto da experiência grupal partilhada. Trata-se, pois, de "uma memória que não se refere apenas ao passado, mas que serve para prever o futuro, para antecipar, permitindo evitar possíveis erros no exercício da atividade" (Lima, 2007, p. 50).

80 A consolidação de um gênero profissional entre os operadores de escavadeira seria uma alternativa para o fortalecimento do trabalho como promotor de saúde e mesmo de produtividade. Porém, para que esse gênero se consolide, enquanto instância saudável e não adoecedora, é fundamental a implantação de práticas cooperativas em torno da atividade. Atualmente, observa-se que a cooperação entre os operadores de escavadeira pode ser considerada incipiente e segmentada, ocorrendo de forma episódica e circunstancial.

81 Vale lembrar que o gênero profissional não depende de intervenções para que surja entre os trabalhadores. Mas, certamente, pode vir a consolidar-se, a partir do diálogo sobre o trabalho, que reconheça a pertinência e a importância dos diferentes saberes e garanta a participação efetiva dos trabalhadores no seu próprio fazer. Trata-se não somente de uma percepção da equipe de pesquisa, mas dos próprios trabalhadores, quando afirmam:

[uma] dificuldade que a gente tem muito é com relacionamento, com as próprias pessoas que estão na frente, tem uns caras "cabeça dura", cara que não entende a tua parte, entendeu? [...] 0 técnico e os que acompanham ele [...] não são participativos. Ele não participa a gente, eles pegam o mapa $\mathrm{e}$ não chamam a gente, acham que nós somos mais um que não sabe de nada (E13).

82 Identifica-se aqui o cenário que alguns autores, ligados ao campo da Ergonomia da Atividade, chamam de "silêncio organizacional", entendido como o "predomínio de situações nas quais os operadores escolhem guardar para si as suas opiniões e preocupações em relação aos problemas organizacionais" (Rocha, 2016, pp. 113-114). Para esse autor, é justamente na formalização e no reconhecimento de espaços voltados para o debate sobre o trabalho que residem as maiores possibilidades de desenvolvimento dos indivíduos e da organização.

Entende-se que a própria pesquisa-intervenção, a partir de seu viés clínico, tem criado condições para que os debates acerca das formas de realizar a atividade apareçam e circulem pelo coletivo, gerando o que Clot (2010) aponta como "uma atividade sobre a 
atividade". O uso dos métodos citados, nesse contexto, mostrou-se pertinente, já que permite que os trabalhadores conduzam o debate. Além disso, reduzem a distância entre o seu saber adquirido na experiência e a nossa necessidade, enquanto pesquisadores, de entender o que fazem. A filmagem e o debate sobre ela, simples e cruzado, por exemplo, desloca o trabalhador de sua posição tradicional para um observador-comentador da atividade, colocando em palavras e elaborando a experiência.

Cabe, porém, cuidar para que a participação e o acesso aos saberes dos trabalhadores não sejam vistos sob a ótica funcionalista, de apropriação do seu conhecimento tácito, unicamente em função do aumento da produção. Defende-se aqui uma compreensão bem próxima de St-Vincent, Toulouse e Bellemare (2000):

Para nós, a abordagem participativa é uma forma particular de intervenção que envolve a criação, dentro da empresa, de uma estrutura de intervenção que define os papéis e mandatos de cada um. Essa estrutura de intervenção prevê mecanismos, como um comitê de pilotagem, por meio do qual as soluções propostas pelas pessoas implicadas estarão sujeitas a um processo de tomada de decisão. Assim, os participantes estão envolvidos no diagnóstico e na busca de soluções, mas também na sua implementação (p. $5)$.

É neste sentido que, a partir da escuta atenta dos trabalhadores e da discussão das análises preliminares aqui apresentadas, propusemos a criação de um "comitê de pilotagem", expressão que tomamos emprestada dos autores acima, ainda em fase de discussão com os gestores. Ela abrange um amplo espectro de possibilidades, utilizadas em diferentes pesquisas e intervenções (Kattar, 2016; Oliveira, 2015; Neiva, 2012; Marques \& Ferries, 2011). Nós a utilizamos, aqui, no sentido de um grupo instituído, no interior da organização, de caráter consultivo, reunindo as contribuições dos próprios trabalhadores, situados em diferentes cargos e funções, portadores de distintos saberes.

A instituição desse comitê tem por objetivo a criação de um espaço formal de "cooperação conflitual", conforme expressão de Yves Clot (2016), entre diferentes atores do processo produtivo, por meio do qual se possa romper a hegemonia do pensamento, da parte dos gestores, dando lugar à manifestação dos "saberes investidos" (que envolvem os saberes construídos na experiência) (Schwartz, 2011) ou da "inteligência prática" (Dejours, 2008). Ela poderá, enfim, favorecer a revitalização constante do gênero profissional e da cooperação entre as diversas equipes do sistema de extração mineral. Por tratar-se de uma proposta ainda em construção, optamos por detalhar sua formulação em outro texto.

Defende-se aqui, portanto, a consolidação de estratégias - não só vinculadas à presença da equipe de pesquisa em sua duração limitada, mas para além dela - no intuito de fomentar a participação dos trabalhadores, entendendo-a como aspecto de crucial importância para a revitalização constante do gênero profissional, o que, por sua vez, alinha-se ao aumento da cooperação entre os diversos membros das equipes atuantes nas quatro unidades atuais do sistema de extração mineral.

\section{Considerações finais}

Guardamos o princípio de que relatos de pesquisa ainda em andamento, com resultados preliminares, carregam certa dose de incerteza, distinta do momento tradicional de 
divulgação científica, que pressupõe conclusões consolidadas. Entretanto, fenômenos como as discussões que ora ocorrem no Brasil sobre as consequências sociais e ambientais da prática da mineração - atingindo particularmente os trabalhadores desse campo, em especial no estado de Minas Gerais - indicam a necessidade de ampliação do debate acerca dessa atividade pela comunidade científica.

Neste relato, procuramos indicar, por meio de resultados preliminares de uma pesquisa em andamento, uma alternativa teórica e prática à demanda de formação individualizada do "operador-atleta", idealizada pela instituição, que se apoiou numa suposta personalização da produção de alto desempenho, enquanto habilidade dependente apenas de características individuais. Para isso, argumentamos, em contraposição, que a dimensão coletiva da atividade, promotora da cooperação no trabalho, é um elemento estrutural do processo produtivo, intrínseco ao desenvolvimento do operador, envolvendo tanto o trabalho em duplas quanto o fazer solidário com os demais membros das equipes de produção, na extração mineral aqui estudada.

Até o momento, trabalhamos com instrumentos diversos de coleta de dados entrevistas, observação dialogante, pesquisa documental, instruções ao sósia e autoconfrontações - visando convocar os trabalhadores a refletir sobre a sua atividade, mobilizando diferentes saberes e contemplando as múltiplas dimensões do ofício. Além disso, a proposição de um espaço de interlocução - um comitê de pilotagem representaria a institucionalização de uma intervenção continuada, gerida pelo próprio coletivo de trabalhadores, mesmo após o encerramento de nossa atividade de pesquisadores. Mais uma vez, visamos romper a lógica individualista do desenvolvimento das atividades específicas, contrapondo-nos aos modelos gerenciais que desconhecem ou desvalorizam o savoir-faire dos trabalhadores.

91 A aplicação dos princípios teórico-metodológicos da Clínica da Atividade, nesse projeto, entre outras contribuições das chamadas clínicas do trabalho, constitui-se como aposta de que se pode contribuir, de modo diferenciado, em consonância com a organização, para o desenvolvimento criativo da atividade, através do incremento multifacetado da cooperação entre os trabalhadores.

\section{BIBLIOGRAFIA}

Abrahão, J. I., \& Pinho, D. L. M. (2000). As transformações do trabalho e desafios teóricometodológicos da Ergonomia. Estudos de Psicologia (Natal), 7(spe), 45-52. https://dx.doi.org/ 10.1590/S1413-294X2002000300006

Amaral, J. C. A. (2016). Contribuições da psicologia do trabalho para a investigação de acidentes em uma empresa de mineração do município de Belo Horizonte (Dissertação de Mestrado). Pontifícia Universidade Católica de Minas Gerais, Belo Horizonte, MG, Brasil.

Aubert, N., \& Gaulejac, V. (1991). Le coût de l'excellence. Paris: Seuil.

Aubert, N. (2003). Le culte de l'urgence. Paris: Flammarion. 
Bardin, L. (1977). Análise de conteúdo. Lisboa: Edições 70.

Bendassolli, P. F., \& Soboll, L. A. (2011). Clínicas do trabalho: filiações, premissas e desafios. Cadernos de Psicologia Social do Trabalho, 14(1), 59-72. https://doi.org/10.11606/issn.

1981-0490.v14i1p59-72

Canguilhem, G. (2016). Meio e normas do homem no trabalho. Pro-Posições, 12(2-3), 109-121. Retirado em 31 março, 2019, de https://periodicos.sbu.unicamp.br/ojs/index.php/proposic/ article/view/8643999

Centro de Tecnologia Mineral (2014). Recursos minerais e comunidade: impactos humanos, socioambientais e econômicos. Rio de Janeiro: CETEM/MCTI.

Clot, Y. (2006). Entrevista: Yves Clot. Cadernos de Psicologia Social do Trabalho, 9(2), 99-107. Retirado em 31 março, 2019, de https://bit.ly/2v1o7UY

Clot, Y. (2007a). A função psicológica do trabalho (2a ed.). Petrópolis: Vozes.

Clot, Y. (2007b). Trabalho e sentido do trabalho. In P. Falzon. (Ed), Ergonomia (pp. 265-280). São Paulo: Edgar Blucher.

Clot, Y. (2010). Trabalho e poder de agir. Belo Horizonte: Fabrefactum.

Clot, Y. (2011). Clínica do trabalho e clínica da atividade. In P. F. Bendassolli, \& L. A. Soboll (Orgs.), Clínicas do trabalho: novas perspectivas para a compreensão do trabalho na atualidade (pp. 71-83). São Paulo: Atlas.

Clot, Y. (2013). O ofício como operador de saúde. Cadernos de Psicologia Social do Trabalho, 16(spe1), 1-11. https://doi.org/10.11606/issn.1981-0490.v16ispe1p1-11

Clot, Y. (2016, outubro). Clinique de l'activité: pourquoi et comment? Conferência de abertura do Colóquio Internacional de Clínica da Atividade. São Paulo, Brasil.

Dejours, C. (2008). Sofrimento e prazer no trabalho: a abordagem pela psicopatologia do trabalho. In S. Lancman, \& I. L. Sznelwar, (Orgs.). Christophe Dejours: da psicopatologia à psicodinâmica do trabalho (2a ed., pp. 143-158). Rio de Janeiro: Editora Fiocruz/Brasília: Paralelo 15.

Departamento Nacional de Produção Mineral. (2016). Anuário Mineral Brasileiro: Principais Substâncias Metálicas. Brasília: DNPM.

Dujarier, M. A. (2016). Apports d'une sociologie de l'activité pour comprendre le travail. In Dujarier, M. A., Gaudart, C., Gillet, A., \& Lénel, P. (Orgs.), L'activité en théories: regards croisés sur le travail (pp. 97-130). Toulouse: Octarès.

Ehrenberg, A. (2010). O culto da performance: da aventura empreendedora à depressão nervosa. Aparecida: Ideias e Letras.

Fonseca, J. C. F., \& Oliveira, I. A. (2013). Clínica da atividade no contexto brasileiro: sobre ciências, territórios e compreensões. In A. Pujol, \& C. Dall'Asta (Orgs.), Trabajo, actividad y subjetividad: debates abiertos (Vol. 1, pp. 33-52). Buenos Aires: Creative Commons. Retirado em 31 março, 2019, de https://rdu.unc.edu.ar/bitstream/handle/11086/1211/Libro_TAS_27112013.pdf?sequence=1

Kattar, A. (2016). Itinerário de um pesquisador-interveniente posto à prova em seus próprios desafios de identidade: uma intervenção num estabelecimento escolar no Líbano. Estilos clínicos, 21(2), 455-478. http//dx.doi.org/10.11606/issn.1981-1624.v21i2p455-478

Lhuilier, D. (2014). Prefácio. In P. F. Bendassolli, \& L. A. Soboll (Orgs.). Métodos de Pesquisa e Intervenção em Psicologia do Trabalho: clínicas do trabalho (pp. 7-11). São Paulo: Atlas. 
Lima, F. P. A. (2002). Ética e trabalho. In I. B. Goulart (Org.), Psicologia organizacional e do trabalho (Vol. 1, 1a ed., pp. 69-120). São Paulo: Casa do Psicólogo.

Lima, M. E. A. (2007). Contribuições da Clínica da Atividade para o campo da segurança no trabalho. Revista Brasileira de Saúde Ocupacional, 32(115), 99-107. http://dx.doi.org/10.1590/ S0303-76572007000100009

Marques, S., \& Ferries, B. (2011). Quadro sinóptico de três iniciativas de incentivo do BIM no contexto francês. Anais do Encontro de Tecnologia de Informação e da Comunicação na Construção (TIC). Salvador, Brasil. Retirado em 31 março, 2019, de https://goo.gl/1cZ7To

Mesquita, A. L. A., Marotta, P. M. T., Athar, A. A. A., \& Sebe, J. (2011). Programa de desenvolvimento, capacitação e disseminação de novas tecnologias - ação desenvolvida pelo governo do estado Pará e Vale S.A. Anais do Congresso Brasileiro de Educação em Engenharia (COBENGE). Blumenau, SC, Brasil, 39. Retirado em 31 março, 2019, de http://www.abenge.org.br/ cobenge/arquivos/8/sessoestec/art1974.pdf

Monteiro, R. P., Araújo, J. N. G., \& Fonseca, J. C. F. (2018, outubro). Estratégias políticas no manejo clínico do trabalho: uma experiência no ramo da mineração. Simpósio França-América Latina sobre Subjetividade e Trabalho. La Habana, Cuba.

Neiva, A. G. (2012). Análise do processo de implementação de um comitê de melhorias das condições de trabalho em uma instituição pública de saúde (Dissertação de mestrado). Universidade de São Paulo, São Paulo, SP, Brasil.

Oliveira, M. M. (2015). Metodologia Interativa: um processo hermenêutico dialético. Interfaces Brasil/Canadá, 1(1), 67-80. http://dx.doi.org/10.15210/interfaces.v1i1.6284

Osório, C., Barros de Barros, M. E., \& Louzada, A. P. (2011). Clínica da atividade: dos conceitos às apropriações no Brasil. In P. F. Bendassolli \& L. A. Soboll (Orgs.), Clínicas do Trabalho: novas perspectivas para a compreensão do trabalho na atualidade (pp. 188-207). São Paulo: Atlas.

Palmeira, F. M. F. (2013). Sistema truckless: uma alternativa sustentável ao setor de mineração brasileiro (Dissertação de mestrado). Universidade Federal de Ouro Preto, Ouro Preto, MG, Brasil.

Pinheiro, K. A., Olveira, E., \& Mesquita, A. L. A. (2016). Sistema truckless e dimensionamento de transportadores de correia. Anais do Congresso Amazônico de Meio Ambiente e Energias Renováveis (CAMAER), Belém, PA, Brasil, 2. Retirado em 31 março, 2019, de https://www.even3.com.br/anais/ camaer2016/30811-sistema-truckless-e-dimensionamento-de-transportadores-de-correia

Rocha, R. (2016). Do silêncio organizacional aos espaços de debate sobre o trabalho: efeitos sobre a segurança e sobre a organização. In F. P. A. Lima, L. Rabelo \& M. Castro (Eds.), Conectando saberes: dispositivos sociais de prevenção de acidentes e doenças no trabalho (1a ed., pp. 111-140). Belo Horizonte: Fabrefactum.

Samulsky, D. M. (2009). Psicologia do esporte: conceitos e novas perspectivas (2a ed.). Barueri: Manole.

Santos, M. (2006). Análise psicológica do trabalho: dos conceitos aos métodos. Laboreal, 2(1), 34-41. Retirado em 31 março, 2019, de http://laboreal.up.pt/revista/artigo.php?id=37t45nSU5471122651 6545:581

Schwartz, Y. (1996). Os ingredientes da competência: um exercício necessário para uma questão insolúvel. Educação e Sociedade, 19(65), 101-140. https://dx.doi.org/10.1590/

S0101-73301998000400004

Schwartz, Y. (2011). Manifesto por um ergoengajamento. In P. F. Bendassolli \& L. A. Soboll (Orgs.), Clínicas do Trabalho: novas perspectivas para a compreensão do trabalho na atualidade (pp. 132-166). São Paulo: Atlas. 
Silva, C. O. (2014). Pesquisa e intervenção em clínica da atividade: a análise do trabalho em movimento. In P. F. Bendassolli \& L. A. Soboll (Orgs.), Métodos de Pesquisa e Intervenção em Psicologia do Trabalho: clínicas do trabalho (pp. 83-99). São Paulo: Atlas.

St-Vincent, M., Toulouse, G., \& Bellemare, M. (2000). Démarches d'ergonomie participative pour réduire les risques de troubles musculo-squelettiques: bilan et réflexions. Pistes, 2(1), 1-33.

https://dx.doi.org/10.4000/pistes.3834

Thiollent, M. J. M. (2008). Concepção e organização da pesquisa. In Metodologia da pesquisa-ação (16a ed., pp. 51-78). São Paulo: Cortez.

\section{RESUMOS}

Este artigo discute os resultados preliminares de uma pesquisa sobre o trabalho de operadores de escavadeira a cabo na extração de minério de ferro. A investigação responde à demanda da empresa, que busca desenvolver um programa de operadores "de alto desempenho". Baseados nos pressupostos teórico-metodológicos da Clínica da Atividade, utilizando entrevistas, observação de campo, instruções ao sósia e autoconfrontação, tomamos como questão analítica central a natureza coletiva do trabalho, articulada à noção de cooperação. Trata-se de uma alternativa prático-teórica, oposta à demanda de formação individualizada, limitada ao "operador-atleta". Entende-se que a dimensão coletiva é uma instância fundante da cooperação, estruturando o processo produtivo e o fazer solidário das equipes de trabalho. Resultados preliminares evidenciam que, apesar de a organização não privilegiar a lógica da cooperação nas exigências de produtividade e na preservação da saúde e segurança dos trabalhadores, ela se abre ao debate sobre essa nova perspectiva do trabalho coletivo.

Este artículo discute los resultados preliminares de una investigación sobre el trabajo de operadores de excavadora por cable en la extracción de mineral de hierro. La investigación responde a la demanda de la empresa, que busca desarrollar un programa de operadores de "alto rendimiento". Basándonos en los supuestos teórico-metodológicos de la clínica de la Actividad, utilizando entrevistas, observación de campo, instrucciones al doble y auto confrontación, valorizamos la naturaleza colectiva del trabajo, bajo la noción de cooperación. Se trata de una alternativa práctica-teórica, opuesta a la demanda de formación individualizada, limitada al "operador-atleta". Se entiende que la dimensión colectiva de la actividad funda la cooperación y aporta estructura al proceso productivo y a la solidaridad en los equipos de trabajo. Los resultados preliminares evidencian que, aunque la organización no privilegia la lógica de la cooperación en las exigencias de productividad y en la preservación de la salud y seguridad de los trabajadores, la misma está dispuesta al debate sobre esta nueva perspectiva del trabajo colectivo.

Cet article met en débat les résultats préliminaires d'une recherche sur le travail d'opérateurs d'excavatrices à câble, dans l'extraction de minerai de fer. L'investigation répond à une demande d'une entreprise qui cherchait à développer un programme de formation d'opérateurs « à haute performance ». Basés sur les présupposés théorico-méthodologiques de la Clinique de l'Activité, en utilisant l'entretien, l'observation de terrain, l'instruction au sosie et l'autoconfrontation, on a mis en évidence la nature collective du travail, articulée à la notion de coopération. On présente ainsi une alternative à la demande de formation individualisée, restreinte à une conception de « l'opérateur-athlète ". On avance l'hypothèse que la dimension collective de l'activité fonde la coopération, structurant le processus productif et la solidarité entre les travailleurs. Les résultats préliminaires montrent que, même si l'organisation ne privilégie pas la logique de la coopération 
dans les exigences de productivité, de préservation de la santé et la sécurité au travail, elle envisage de débattre cette perspective du travail collectif.

This paper discusses the preliminary results of a research on the work of cable excavators in the extraction of iron ore. The research responds to the demand of the company, which seeks to develop a program of "high-performance" operators. Based on assumptions of the clinic of Activity, using interviews, field observation, instructions to the look-alike and self-confrontation, we focus on the collective nature of the work, articulated with the notion of cooperation. That practical-theoretical alternative is opposed to the demand for individualized training, limited to the "operator-athlete". It is understood that the collective dimension of the activity bases the cooperation, structuring the productive process and the solidarity of the work teams. Preliminary results show that, although the organization does not privilege the logic of cooperation in the demands of productivity and in the preservation of workers' health and safety, it opens for the debate on this new perspective of collective work.

\section{ÍNDICE}

Mots-clés: exploitation minière, travail collectif, haute performance, clinique de l'activité Keywords: mining, collective work, high performance, clinic of activity

Palavras-chave: mineração, trabalho coletivo, alto desempenho, clínica da atividade

Palabras claves: minería, trabajo colectivo, alto rendimiento, clínica de la actividad

\section{AUTORES}

\section{JOÃO CÉSAR DE FREITAS FONSECA}

Programa de Pós-Graduação em Psicologia da PUC Minas. Avenida Itaú, 525, Dom Cabral, 30535012 - Belo Horizonte, MG - Brasil, E-mail: joaocesar@pucminas.br

\section{JOSÉ NEWTON GARCIA DE ARAÚJO}

Programa de Pós-Graduação em Psicologia da PUC Minas. Avenida Itaú, 525, Dom Cabral, 30535012 - Belo Horizonte, MG - Brasil, E-mail: jinga@uol.com.br

\section{CARLOS EDUARDO CARRUSCA VIEIRA}

Programa de Pós-Graduação em Psicologia da PUC Minas. Avenida Itaú, 525, Dom Cabral, 30535012 - Belo Horizonte, MG - Brasil, E-mail: carlos.carrusca@outlook.com

\section{RODRIGO PADRINI}

Programa de Pós-Graduação em Psicologia da PUC Minas. Avenida Itaú, 525, Dom Cabral, 30535012 - Belo Horizonte, MG - Brasil, E-mail: rodrigopadrini@gmail.com 